\title{
Terapi Akupreseur untuk Penurunan Nyeri Haid
}

\author{
Acupressure Therapy for Menstrual Pain Reduction
}

\author{
Neny Yuli Susanti \\ Universitas Ibrahimy \\ Email: nenyyulisusanti@gmail.com
}

\begin{abstract}
ABSTRAK
Berdasarkan survey dari WHO memperlihatkan bahwa remaja usia 17-21 tahun $80 \%$ mengalami nyeri haid. Nyeri haid atau disminore biasa disebut dengan kondisi yang mengurangi kenyamanan saat beraktivitas dan sebagian besar perempuan saat menstruasi dan tidak melihat usia dengan jumlah mayoritas di saat remaja awal dan baru mengalami menstruasi awal. Salah satu penanganan nyeri haid secara non farmakologis adalah dengan terapi akupreseur. Tujuan penelitian ini adalah mengetahui penurunan nyeri haid setelah pemberian terapi akupreseur. Desain penelitian ini adalah pra experiment (one group pre test post test). Pelaksanaan penelitian dilakukan selama 3 bulan. Populasi dalam penelitian ini adalah seluruh remaja putri di Pondok Pesantren Salafiyah Syafiiyah Situbondo dan besar sampel 30 remaja putri. Intrument penelitian berupa lembar observasi dan kuesioner dengan teknis accidental sampling. Dari hasil analisa data SPSS didapatkan mean 5,43 untuk tingkat nyeri sebelum terapi akupreseur dan mean 2,83 untuk tingkat nyeri sesudah terapi akupreseur. Akupreseur merupakan salah satu bentuk terapi sederhana untuk menurunkan nyeri haid. Penelitian ini dapat digunakan sebagai referensi dalam pengembangan asuhan alternatif kebidanan yang berkaitan dengan penurunan nyeri haid pada remaja putri dengan teknik akupreseur.
\end{abstract}

Kata kunci : Terapi Akupreseur, Nyeri Haid

\begin{abstract}
Based on a survey from the WHO showed that $80 \%$ of adolescents aged 17-21 years experienced menstrual pain. Menstrual pain or dysmenorrhea is a condition that bothers most women during menstruation regardless of age, with the highest percentage in their early teens experiencing menarche. One of the non-pharmacological treatment of menstrual pain is acupressure therapy. The purpose of this study was to determine the decrease in menstrual pain after giving acupressure therapy. The design of this research is pre-experimental (One group pre-test post-test). The research was carried out for 3 month. The population in this study were all young women at the Salafiyah Syafiiyah Islamic Boarding School in Situbondo and the sample size was 30 young women. The research instruments were in the form of observation sheets and questionnaires with accidental sampling technique. From the results of SPSS data analysis, it was found that the mean was 5.43 for the level of pain before acupressure therapy and the mean was 2.83 for the level of pain after the acupressure therapy. Acupressure is a simple form of therapy to reduce menstrual pain. This study can be used as a reference in developing alternative midwifery care related to reducing menstrual pain in adolescent girls with acupressure techniques.
\end{abstract}

Keywords: Acupressure Techniques, Menstrual Pain

\section{PENDAHULUAN}

Nyeri haid atau disminore biasa

$\begin{array}{lr}\text { disebut dengan kondisi } & \text { yang } \\ \text { mengurangi } & \text { kenyamanan } \\ \text { beraktivitas dan sebagian } & \text { besar }\end{array}$

perempuan saat menstruasi dan tidak melihat usia dengan jumlah terbanyak di usia remaja awal yang baru mengalami menstruasi awal. Disminore bisa disebut juga dengan kata lain gangguan atau ketidaknyamanan yang bersifat symptomatic artinya hal 
tersebut bukan merupakan suatu penyakit tetapi suatu gejala yang timbul dan dapat menyebabkan rasa ketidaknyamanan (Gant \& Cunningham, 2016). Proses disminore yaitu pada proses poliferasi kearah proses sekresi terjadi penambahan jumlah prostaglandin di area endometrium secara lebih dari biasanya dan dapat mengakibatkan terjadinya kontraksi pada miometrium sehingga terjadi iskemik yang selanjutnya diikuti dengan pengurangan jumlah progesteron pada akhir proses luteal. Hal ini menimbulkan nyeri di otot uterus sebelum, saat, dan setelah masa haid (Nugroho, 2015).

Hasil survei World Health Organization (WHO) tahun 2013 memperlihatkan bahwa lebih dari $80 \%$ perempuan usia subur mengalami disminore saat haid, dan $67,2 \%$ nya terjadi pada kelompok usia 13-21 tahun. Mayoritas perempuan di Indonesia yang mengalami dismenorea tidak terlaporkan atau berkunjung ke dokter. Hampir $100 \%$ perempuan di Indonesia pernah menderita nyeri haid (Gumangsari, 2014). Prevalensi angka kejadian nyeri haid di Indonesia berdasarkan Jurnal Occupational Environtmental cukup banyak yaitu
$54,98 \%$ dismenore primer dan $9,36 \%$ dismenore sekunder. Disminore atau nyeri haid terbagi menjadi dua yaitu disminore primer dan disminore sekunder. Perempuan dikatakan mengalami disminore primer jika terjadi nyeri ketika haid dan tidak ditemukan kelainan pada genetalia, sedangkan disminore sekunder terjadi nyeri saat haid dan terdapat kelainan yang mengikuti seperti flour albus (Irianto, 2015).

Akupreseur merupakan bentuk fisioterapi dengan pemberian terapi pemijatan dan rangsangan pada titiktitik tertentu pada tubuh (garis aliran energi atau meridian) untuk mengurangi nyeri (Widyaningrum, 2013). Akupreseur pada penelitian ini menggunakan terapi dengan teknik tuina yang disebut juga anmo yaitu bagian paling penting dari Traditional Chinese Medicine (TCM). Terapis (pelaksana) melakukan gerakan manipulasi atau gerakan tuina pada permukaan tubuh pasien berdasarkan pada kondisi pasien, dan jenis penyakit yang diderita. Manipulasi atau gerakan yang diberikan bisa berupa dengan mendorong, dengan memegang, dengan menggosok, dengan menekan, dengan memijat, dengan memukul, dan dengan 
tindakan sederhana lain pada titik akupoin atau pada daerah tertentu di permukaan tubuh. Penekanan yang diberikan pada titik bisa menekan jumlah prostaglandin sehingga jumlah prostaglandin mengalami penurunan dan mampu memberikan rangsangan tubuh untuk dapat menghasilkan hormone endorphin (Hendrata, 2012).

\section{METODE PENELITIAN}

Penelitian ini merupakan penelitian kuantitatif dengan desain pra experiment (One group pre test post test). Pengukuran nyeri menggunakan skala likert 1 sampai 6 untuk tingkatan nyeri. Tindakan akupresur dengan teknik tuina yang dilakukan untuk semua diagnosa dan dilakukan 2 kali setiap hari selama haid dengan durasi waktu 15 menit yaitu:

1. Teknik menggosok bagian atas perut secara transversal dan ulangi gerakan 5-10 menit.

2. Teknik menggosok bagian atas pubis secara transversal dan ulangi gerakan 5-10 menit.

3. Teknik penekanan sepanjang medial tulang iliaka dan ulangi gerakkan 1-2 menit.
4. Teknik menggosok dada pada bilateral dan ulangi gerakan 1-3 menit.

5. Teknik meremas dan mencubit sepanjang medial paha, remas dan cubit otot bagian tengah dan ulangi gerakan 3-5 menit.

6. Teknik memencet dan menekan bagian tulang belakang dan ulangi gerakan 3-5 menit.

7. Teknik menekan dengan ibu jari pada bagian tulang belakang (lumbal) pada titik bilateral dan ulangi gerakan 1-3 menit.

Kriteria eksklusi dalam penelitian ini adalah remaja putri yang mengalami nyeri haid dalam kategori patologi (menunjukkan gejala nyeri lebih dari normal, contoh sampai pingsan dan nyeri berat). Lokasi penelitian ini dilaksanakan di Pondok Pesantren Salafiyah Syafi'iyah Sukorejo Situbondo. Penelitian ini membutuhkan waktu 3 bulan dimulai dari pengambilan data sampai hasil penelitian sedangkan untuk pemberian intervensi terapinya adalah 1 minggu. Populasi pada penelitian ini adalah seluruh remaja putri di lingkungan Pondok Pesantren Salafiyah Syafi'iyah Sukorejo Situbondo. Sampel pada penelitian ini sejumlah 30 responden. 
Pengumpulan data dilakukan dengan uji mean untuk melihat penurunan tingkat nyeri sebelum dan sesudah penelitian.

\section{HASIL DAN PEMBAHASAN}

Tabel 1. Distribusi Karakteristik Responden.

\begin{tabular}{ccc}
\hline Data Umum & Frekuensi & Persentase \\
\hline Umur & & \\
$17-19$ & 17 & $56 \%$ \\
$20-21$ & 13 & $43 \%$ \\
Total & 30 & $100 \%$ \\
Pendidikan & & \\
SMA & 16 & $53 \%$ \\
PT & 14 & $46 \%$ \\
Total & 30 & $100 \%$ \\
\hline
\end{tabular}

Berdasarkan data diatas didapatkan bahwa sebagian besar umur responden 17-19 tahun dan sebagian besar pendidikan responden adalah SMA.

Tabel 2. Tingkat Nyeri Haid Sebelum Dilaksanakan Akupreseur Pada Remaja Putri

\begin{tabular}{ccc}
\hline $\begin{array}{c}\text { Tingkat Nyeri } \\
\text { Haid }\end{array}$ & Frekuensi & Mean \\
\hline 3 & 3 & \\
4 & 6 & \\
5 & 6 & 5,43 \\
6 & 8 & \\
7 & 4 & \\
8 & 3 & \\
Total & 30 & \\
\hline
\end{tabular}

Berdasarkan data diatas didapatkan bahwa sebagian besar responden mengalami tingkat nyeri 6 yaitu sebanyak 8 responden.
Tabel 3. Tingkat Nyeri Haid Setelah Dilaksanakan Akupreseur Pada Remaja Putri

\begin{tabular}{ccc}
\hline $\begin{array}{c}\text { Tingkat Nyeri } \\
\text { Haid }\end{array}$ & Frekuensi & Mean \\
\hline 1 & 4 & \\
2 & 9 & \\
3 & 11 & 2,83 \\
4 & 4 & \\
7 & 2 & \\
Total & 30 & \\
\hline
\end{tabular}

Berdasarkan data diatas didapatkan bahwa sebagian besar responden mengalami tingkat nyeri 3 yaitu sebanyak 11 responden.

Menurut tabel 2 memperlihatkan bahwa sebelum pemberian terapi akupreseur sebagian besar dari responden yang merupakan usia remaja mengalami tingkat 6 nyeri haid dengan nilai rata-rata 5,43. Nyeri haid merupakan sakit atau nyeri pada perut bagian bawah dan terkadang tembus sampai pinggang dan dirasakan sebelum haid sampai dengan hari 1 sampai hari ke 2 haid sehingga membuat penderita harus istirahat untuk tidak melakukan aktivitas selama beberapa waktu.

Berdasarkan hasil dari beberapa penelitian penyebab dari nyeri haid adalah peningkatan jumlah hormon prostaglandin yang dapat memicu terjadinya kontraksi uterus, ditambah juga dengan pola makan remaja putri yang tidak sesuai dengan ketentuan 
makan pada umumnya (tidak teratur). Hal ini bias menjadi penyebab utama dari nyeri haid karena kontraksi myometrium diimbangi dengan meningkatnya asam lambung maka menyebabkan nyeri haid.

Menurut Tabel 3 memperlihatkan bahwa sesudah diberikan terapi akupreseur sebagian besar remaja putri mengalami penurunan tingkatan nyeri yaitu ratarata 2,83 maka dapat disimpulkan bahwa sesudah diberikan terapi remaja putri mengalami efek penurunan tingkat nyeri haid sebesar 2,6. Penurunan intensitas nyeri haid ini dialami oleh remaja putri bias dikarenakan efek analgesic yang terdapat pada terapi akupreseur. Berdasarkan penelitian sebelumnya yang dilakukan oleh Aprilia pada tahun 2015 mengemukakan bahwa teknik akupreseur dapat mengurangi rasa nyeri melalui peningkatan hormone endorphin yaitu hormon yang mempunyai kemampuan menghadirkan rasa santai pada tubuh secara alamiah, memblok reseptor nyeri yang menuju ke otak. Hal yang serupa juga disampaikan oleh Hartono pada hasil penelitian di tahun 2012 bahwa terapi akupreseur sudah terbukti bisa membantu produksi hormon endorphin di otak yang secara alamiah bisa membantu mengurangi rasa sakit saat menstruasi. Penekanan pada titik akupreseur bias memberikan pengaruh terhadap produksi endorphin dalam tubuh, sehingga terjadi dampak analgesik untuk mengurangi nyeri haid yang dirasakan. Peneliti saat melakukan semua remaja putri yang mengalami nyeri haid mengalami pengurangan tingkat nyeri haid. Remaja putri yang mengalami nyeri haid diberikan akupreseur sebanyak satu kali selama 20-30 menit sesuai dengan diagnosa nyeri haid yang dialami, sehingga tingkat penurunan nyeri haid yang dirasakan berbeda-beda.

\section{SIMPULAN DAN SARAN}

Simpulan penelitian ini adalah Remaja putri yang sedang nyeri haid sebelum dilakukan terapi akupreseur rata-rata mengalami tingkat nyeri haid sebesar 5,43. Responden penelitian yang sedang nyeri haid sesudah dilakukan terapi akupreseur rata-rata mengalami tingkat nyeri haid sebesar 2,83 dan Penelitian ini dapat digunakan sebagai referensi dalam pengembangan asuhan alternatif kebidanan yang berkaitan dengan pengurangan nyeri haid khususnya pada remaja putri dengan teknik akupreseur. 
DAFTAR PUSTAKA

Alfabeta. Ju H, Jones M, Mishra G. 2012. Kesehatan Reproduksi (Reproductive Health Teori \& Praktikum). The prevalence and risk of dysmenorrhea.Oxford University Press. (2013); 36(1):104-13. Bandung.

Bavil, D.A., Dolatian, M., Mahmoodi, Z., Baghban, Alireza, A. (2016). Comparison of Lifestyles of Young Woman with and Without Primary Dysmenorrhea.

Brunner \& Suddarth. (2012).Buku Ajar Keperawatan Medikal Bedah, alih bahasa.EGC, Jakarta.

Gant, Norman dan Gary Cunningham.Electronic. 2016. Journal Physician. Vol. 8 (3) : 2107-2114. Dasar Dasar Ginekologi \& Obstetri. EGC. Jakarta.
Irianto, 2015.Koes Traditional Chinese Medicine. Surabaya: INORMEC (Indonesian Oriental Medicine Education Centre).

Laila, Nur Najmi. 2011. Kesehatan Reproduksi untuk Mahasiswa Keperawatan dan Kebidanan : Salemba Medika. Jakarta.

Nugroho, Taufan. 2014.Pengaruh minuman kunyit terhadap tingkat nyeri dismenore primer pada remaja putri di SMA Negeri 1 Tanjung Mutiara Kabupaten Agam (disertasi). Padang: Universitas Andalas. Buku Ajar Ginekologi untuk Mahasiswa Kebidanan. Nuha Medika. Yogyakarta.

Parker MA, Sneddon AE, Arbon P. 2014.Masalah Kesehatan Reproduksi Wanita.Yogyakarta : Nuha Medika. Yogyakarta. 